Research Article

\title{
Green Synthesis of Silver Nanoparticles Using Waste Products (Apricot and Black Currant Pomace) Aqueous Extracts and Their Characterization
}

\author{
Georgii Vasyliev (D), ${ }^{1}$ Victoria Vorobyova ${ }^{D},{ }^{1}$ Margarita Skiba $\left(\mathbb{D},{ }^{2}\right.$ and Liudmyla Khrokalo \\ ${ }^{1}$ Department of Chemical Technology, National Technical University of Ukraine "Igor Sikorsky Kyiv Polytechnic Institute", \\ Kyiv 03056, Ukraine \\ ${ }^{2}$ Department of Inorganic Materials Technology and Ecology, Ukrainian State University of Chemical Technology, \\ Dnipro 49005, Ukraine
}

Correspondence should be addressed to Georgii Vasyliev; g.vasyliev@kpi.ua

Received 18 March 2020; Revised 18 May 2020; Accepted 15 June 2020; Published 13 July 2020

Academic Editor: Stefano Bellucci

Copyright (c) 2020 Georgii Vasyliev et al. This is an open access article distributed under the Creative Commons Attribution License, which permits unrestricted use, distribution, and reproduction in any medium, provided the original work is properly cited.

\begin{abstract}
An eco-friendly and low-cost method for synthesizing and capping silver nanoparticles with aqueous extracts of apricot and currant wastes is reported. The chemical profiles of the extracts were analysed using liquid chromatography-mass spectrometry (LC-MS). Total phenolic content and total flavonoid content of extracts were determined. The antioxidant activity of the synthesized nanoparticles was evaluated by DPPH (1,1-diphenyl-2-picrylhydrazyl) power assays. Cyclic voltammetry study was performed to determine the reducing ability of the aqueous extract of the black currant and apricot pomaces. Characterization of AgNPs was carried out using energy-dispersive X-ray spectroscopy (EDS), X-ray diffraction (XRD), scanning electron microscopy (SEM), and UV-visible spectroscopy. Zeta potential of obtained colloidal solutions varies from -33.41 to $-24.23 \mathrm{mV}$ indicating the moderate stability of synthesized nanoparticles. The synthesized nanoparticles efficiently demonstrated a bactericide effect on Escherichia coli.
\end{abstract}

\section{Introduction}

One of the key trends in the development of the modern field of nanotechnology is the concept of environmental safety and the introduction of "green" technologies [1-4]. A fundamental key to the strategy of the "green" synthesis of metal nanoparticles is the use of low-cost, environmentally friendly, and renewable materials. "Green"/biogenic/phytochemical synthesis or biosynthesis of metallic nanoparticles is known to be a simple, ecological, cost-effective, cheap technique and is much safer for humans as compared to the conventional physical, chemical, and electrochemical methods [5-9]. Notably, plants in agricultural and timber industry are found to be rich in "green" organic compounds such as aldehydes, terpene alcohols, polysaccharides, flavonoids, alkaloids, phenolic acids, and polyphenolic compounds and may act as powerful reducing and capping agents in a single-step and one-pot reaction for the production of nanoparticles (NPs) such as silver, gold, or copper [10-15].

From the reported literature, extracts of various parts of plants such as root, seeds, leaves, stem, and flower have been used for the synthesis of metallic nanoparticles. For example, Lakshmanan used the aqueous extract of Cleome viscosa to produce silver particles with the mean sizes between 410 and $430 \mathrm{~nm}$ [16]. The aqueous solution of Origanum vulgare plant extract was also used to synthesize AgNPs [17]. Plants extracts from biomass of Ocimum tenuiflorum, Solanum trilobatum, Syzygium cumini, Centella asiatica, and Citrus sinensis were used for the synthesis of silver nanoparticles (AgNPs) with antibacterial properties [18]. However, the "green" reducing compounds extracted from agricultural 
wastes or agro-food byproducts without harm to plants and environment was seldom reported. This has prompted researchers to search for some cheap and effective "green" reducing agents extracted from fruit and vegetable waste that can be used to produce nanoparticles which is cost-effective for large scale production.

Apricot and black currant are promising sources of "green" organic compounds. The fruit pomaces represent a large portion of waste generated during juice processing (36\% of fruit weight). As fruit pressing is an incomplete extraction process, the pomaces contain a large amount of valuable "green" compounds. Based on this observation, it is appropriate to assess the prospects of the use of plant extracts as a reducing agent to produce nanoparticles, namely, silver (AgNPs). The synthesis of silver nanoparticles using different natural extracts has been also reported because of the great interest in the "green" synthesis of AgNPs used in nanomedicine and microbiological applications.

However, analysis of component composition and preliminary assessment of the reducing ability of plant extracts as indirect comparative parameters affecting the efficiency of nanoparticle synthesis have not been considered elsewhere. In this study, the reducing capacity was characterized using the cyclic voltammetry method, and total phenolic and polyphenolic content were determined to analyse the potential use of apricot and black currant pomaces as a source of reducing agents in the synthesis of nanomaterials. The structural, antimicrobial, electrochemical, and antioxidation properties of produced AgNPs were characterized.

\section{Materials and Methods}

2.1. Extract Preparation. The black currant and apricot extracts, obtained from the pomaces that remained after mechanical pressing of the fresh fruits to produce juices, were assayed for the composition of the main compounds, redox, and antioxidant activity. Black currant or apricot pomaces were mixed with the distilled water in the $1: 10(\mathrm{w} / \mathrm{v})$ ratio at $25^{\circ} \mathrm{C}$. The mixture was placed in the ultrasound bath. The ultrasound of $27 \mathrm{kHz}$ frequency and $6 \mathrm{~W} / \mathrm{cm}^{2}$ intensity was being applied for 2 hours. During the sonication, the air was continuously bubbled through the solution. Due to the high intensity of sonication, the ultrasound cavitation occurs in the solution intensifying the extraction process. In the end of the process, the temperature of the solution reached $40^{\circ} \mathrm{C}$ due to the influence of ultrasound. After the extraction, the solution was filtered through paper filter and used to synthesize AgNPs.

2.2. Characterization of the Pomace Extracts Composition. The obtained extracts were analysed with LC-MC technique. A Finnigan MAT (San Jose, CA, USA) Spectra System P4000 pump was used in with a UV6000LP diode array detector and a Finnigan AQA mass spectrometer. Analyses were carried out on a Superspher RP-18, $125 \times 2 \mathrm{~mm}, 4 \mu \mathrm{m}$ column (Macherey-Nagel, Germany), protected by a guard column packed with the same material and maintained at $40^{\circ} \mathrm{C}$. Analyses were performed using electrospray ionization (ESI) in the positive ion mode, with acquisition set at 12 and $50 \mathrm{eV}$, capillary voltage at $4 \mathrm{kV}$, source voltage at $4.9 \mathrm{kV}$, detector voltage at $650 \mathrm{~V}$, and probe temperature at $400^{\circ} \mathrm{C}$. Eluent A and eluent B were $2.5 \%$ acetic acid and methanol, respectively. The flow rate was $0.33 \mathrm{~mL} \mathrm{~min}^{-1}$, and the elution program used was as follows: $0-5 \mathrm{~min}, 0 \% \mathrm{~B}$; 5-30 min, $100 \%$ B; $30-35$ min, $100 \%$ B.

2.3. Synthesis of AgNPs by Using Pomace Extracts. The 10-30 mL portion of each extract was used for the synthesis of AgNPs. The equivalent volumes of the extract solution and $0.01 \mathrm{M} \mathrm{AgNO}_{3}$ were heated separately in the glass beakers in the water bath to the temperature of $80{ }^{\circ} \mathrm{C}$. Then, the extract solution was added to the $\mathrm{AgNO}_{3}$ and left on a water bath for $30 \mathrm{~min}$. After this, the heating was turned off and the solution was cooled down to the room temperature. In order to monitor the changes in $\mathrm{Ag}^{+}$concentration during synthesis, an electrochemical technique of chronopotentiometry, consisting of the silver $\left(\mathrm{Ag}^{+} \mid \mathrm{Ag}\right)$ working electrode and saturated silver chloride $\left(\mathrm{Ag}|\mathrm{AgCl}| \mathrm{Cl}^{-}\right)$reference electrode, was used. The potential of the $\mathrm{Ag}^{+} \mid \mathrm{Ag}$ electrode depends on $\mathrm{Ag}^{+}$concentration according to the following Nernst equation:

$$
\mathrm{E}_{\mathrm{Ag}+\mid \mathrm{Ag}}=\mathrm{E}_{\mathrm{Ag}+\mid \mathrm{Ag}}^{0}+\frac{\mathrm{RT}}{\mathrm{F}} \cdot \ln \left(\mathrm{a}_{\mathrm{Ag}^{+}}\right) .
$$

The potential of saturated silver chloride depends on $\mathrm{Cl}^{-}$ concentration and thus remained unchanged during the synthesis. The calibration plot was built to find the correlation between the $\mathrm{Ag}^{+} \mid \mathrm{Ag}$ electrode potential and $\mathrm{Ag}^{+}$ concentration in the range $0.001 \mathrm{M}, \ldots, 0.1 \mathrm{M}$. During the synthesis, the $\mathrm{Ag}^{+} \mid \mathrm{Ag}$ electrode was immersed into the reaction solution and its potential vs. time with a digital multimeter UNI-T UT61B with a $1 \mathrm{mV}$ accuracy was recorded. The change in the potential was used to find the change in $\mathrm{Ag}^{+}$concentration after the synthesis.

\subsection{Characterization of Synthesized Silver Nanoparticles}

2.4.1. UV-Vis Spectrophotometry. The synthesized silver nanoparticles were investigated at regular interval using an UV-Vis spectrophotometer (Shimadzu-2450 UV-vis spectrophotometer) in the range between 200 and $800 \mathrm{~nm}$. The samples were diluted with deionized water and UV-visible spectra were recorded using $1 \mathrm{~cm}$ Quartz cuvette at $25^{\circ} \mathrm{C}$.

2.4.2. Dynamic Light Scattering (DLS). The zeta potential was measured through electrophoretic light scattering at $25^{\circ} \mathrm{C}, 150 \mathrm{~V}$, in triplicate for the sample (Malvern Zetasizer Nano-ZS, Malvern Instruments, UK). The sample was prepared by diluting the $10 \mathrm{ml}$ of the AgNPs solution in $10 \mathrm{ml}$ distilled water. After that, the $10 \mathrm{ml}$ of sample solution was put in the cuvette. The cuvette was placed in the cell holder and scanned in range of 1-100 $\mathrm{nm}$ using a fixed angle of $173^{\circ}$. 
2.4.3. Scanning Electron Microscopy. A scanning electron microscope (SEM) was used to examine the morphology of synthesized AgNPs. A drop of colloidal system of BCPEAgNPs or APE-AgNPs was applied on the carbon-coated copper plate and an image was taken at an acceleration voltage of $10 \mathrm{kV}$. EDX analysis was conducted with the same instrument to confirm the elemental composition of the sample.

2.4.4. X-Ray Diffraction (XRD). Crystalline metallic silver was examined by x-ray diffraction (XRD). The XRD pattern was recorded using Bruker AXS D8 Advance diffractometer (Shimadzu, Japan) with $\mathrm{CuK} \alpha$ radiation monochromatic filter. The diffracted intensities were recorded from 30 to $80^{\circ} 2 \theta$ angles.

2.4.5. Electrochemical Activity. The electrochemical activity of the pomace extracts as well as synthesized nanoparticles was studied using cyclic voltammetry. The three-electrode system was composed of Glassy Carbon Electrode (GCE) as the working electrode, a saturated silver chloride electrode $(E=+0.2 \mathrm{~V} / \mathrm{NHE})$ as the reference electrode, and a platinum plate as an auxiliary one. The potential scan rate was $100 \mathrm{mV} / \mathrm{s}$ in the potential range $0, \ldots,+1.0 \mathrm{~V} / \mathrm{SSCE}$. The portion of the extract or AgNPs solution was mixed with acetate buffer $0.1 \mathrm{M}(\mathrm{pH} 4)$ and $\mathrm{NaClO}_{4}(70: 28: 2)$. Solution temperature was kept at $25^{\circ} \mathrm{C}$.

2.4.6. Fourier-Transform Infrared Spectroscopy (FT-IR). FTIR analysis was performed to investigate the various functional groups of synthesized AgNPs. FT-IR spectra of extracts, BCPE-AgNPs, and APE-AgNPs were measured by Bruker Tensor 27 FTIR spectrometer with a diamond crystal accessory in spectral range of $4000-600 \mathrm{~cm}^{-1}$ with a resolution of $4 \mathrm{~cm}^{-1}$.

2.4.7. Scavenging of 2,2-Diphenyl-1-picrylhydrazyl (DPPH) Radicals. The radical scavenging efficacy of BCPE-AgNPs and APE-AgNPs was determined using DPPH assay [20]. The BCPE-AgNPs and APE-AgNPs were mixed with ethanol at various concentrations. Each dilution $(0.5 \mathrm{~mL})$ was mixed with $3 \mathrm{~mL}$ of an ethanol solution of DPPH $(0.1 \mathrm{mmol})$. The mixture was incubated in the darkness at room temperature and the absorbance of the DPPH solution was measured at $\lambda=517 \mathrm{~nm}$ to $\left(A_{\text {control }}\right) 30$ minutes after adding the extract. In the blank experiment, ethanol was used instead of the sample; BHT (butylated hydroxyl toluene) was used as a positive control. The ability to scavenge the DPPH free radical was calculated using the following equation:

DPPH radical scavenging activity $(\%)=\left(\frac{\mathrm{A}_{\text {control }}-A_{\text {sample }}}{A_{\text {control }}}\right) \times 100$.

2.4.8. Antibacterial Properties. Escherichia coli strain UKM B-906 was used as object for estimation of antimicrobial effect of silver nanoparticles disperse system. Active concentrations estimation in liquid medium of meat-peptone broth was conducted by the method of standard evaluation of the antibiotics action [19]. In the set of tubes that contained $2 \mathrm{~cm}^{3}$ of nutrient medium, $2 \mathrm{~cm}^{3}$ of AgNPs disperse system with different concentration was added as well as $2 \mathrm{~cm}^{3}$ of $E$. coli inoculum. In control tube, $2 \mathrm{~cm}^{3}$ of medium, $2 \mathrm{~cm}^{3}$ of aseptic distilled water, and $2 \mathrm{~cm}^{3}$ of inoculum were put. All tubes were incubated at $37^{\circ} \mathrm{C}$ for 24 hours. The results were evaluated as the difference in the optical density of the suspensions by photoelectric colorimeter at $\lambda=540-670 \mathrm{~nm}$. Visual analysis of the bacteria growth on the selective medium Endo agar was used as an additional control.

Minimal bactericidal concentration (MBC) was determined as the lowest concentration of AgNPs solution in the tube in which there were not any significant changes of turbidity and no colony in Endo agar was detected. Minimal inhibitory concentrations (MIC) were estimated as the concentration in tube in which turbidity (optical density) was doubly decreased compared to control.

\section{Results and Discussion}

3.1. Extract Characterization. The water extracts from black currant and apricot pomaces were analysed by LC-MS. The relative retention times (RT) and mass spectra of the extract's components were compared with those of authentic samples and with mass spectra from a data library. The results of LC-MS of the apricot and black currant pomace extracts are shown in Table 1. Black currant pomaces extract mainly consists of phenolic compounds, predominantly chlorogenic acid (5.4\%), protocatechuic acid (15.6\%), and caffeic acid (10.1\%) and minor quantities of aldehydes and flavonoids. These compounds are known today for their reducing ability [21-25].

A complex mixture of organic compounds was already identified in apricot pomace extract, as flavonoids, phenolic acid derivatives (1-caffeoylquinic acid). Chlorogenic acid (4.6\%), catechin $(5.8 \%)$, and caffeic acid (8.2\%) were found in large amounts in the sample of apricot pomace extract. This extract is characterized by the presence of phenolic compounds such as quinic acid (7.1\%), chlorogenic acid (6.8\%), and kaempferol (5.6\%). The rich source of phenolic acid and flavonoids in a fruit wastes extract might be 
TABLE 1: LC-MS analysis result of aqueous black currant and apricot pomaces extract.

\begin{tabular}{|c|c|c|c|c|}
\hline \multirow{2}{*}{ Compound } & \multicolumn{2}{|c|}{ APE } & \multicolumn{2}{|c|}{$\mathrm{BCPE}$} \\
\hline & $\mathrm{RT}(\min )$ & Percentage & $\mathrm{RT}(\min )$ & Percentage \\
\hline Caffeic acid & 15.14 & 8.2 & 8.04 & 10.1 \\
\hline Naringenin & 18.13 & 5.5 & 8.10 & 5.4 \\
\hline Chlorogenic acid & 19.78 & 6.8 & 9.66 & 5.4 \\
\hline Protocatechuic acid & - & - & 6.69 & 15.6 \\
\hline Apigenin & - & - & 9.28 & 8.8 \\
\hline p-Coumaroylquinic acid & - & - & 9.53 & 0.8 \\
\hline Ferulic acid-O-glucoside & - & - & 9.90 & 0.9 \\
\hline Isoquercitrin (quercetin-3-O-glucoside) & - & - & 11.56 & 7.1 \\
\hline Kaempferol-O-glucoside & - & - & 10.12 & 1.4 \\
\hline Cyanidin-3-O-glucoside & - & - & 10.35 & 8.7 \\
\hline Cynaroside (luteolin-7-O-glucoside) & - & - & 10.68 & 10.1 \\
\hline Narirutin (naringenin-7-O-rutinoside) & - & - & 11.73 & 2.4 \\
\hline Naringenin-O-diglucoside & - & - & 12.43 & 16.9 \\
\hline Quercetin 3-O-diglucoside & - & - & 12.73 & 5.8 \\
\hline 3,4-Dihydroxybenzaldehyde & 13.99 & 3.4 & - & - \\
\hline 4-Hydroxybenzoic acid & 14.93 & 3.8 & - & - \\
\hline 3,4-Dimethoxybenzoic acid & 15.92 & 5.7 & - & - \\
\hline Quinic acid & 16.99 & 7.1 & - & - \\
\hline Kaempferol $\left(3,4^{\prime}, 5,7\right.$ tetrahydroxyflavone $)$ & 17.86 & 3.4 & - & - \\
\hline Catechin & 18.58 & 5.8 & - & - \\
\hline Epicatechin & 19.18 & 7.2 & - & - \\
\hline Caffeic acid-O-glucoside & 21.30 & 5.8 & - & - \\
\hline Delphinidin & 19.27 & 11.8 & - & - \\
\hline Neochlorogenic acid & 22.51 & 2.9 & - & - \\
\hline 1-Caffeoylquinic acid & 22.53 & 4.6 & - & - \\
\hline Kaempferol-O-glucoside & 22.55 & 5.6 & - & - \\
\hline Malvidin 3-O-(6-p-coumaroyl)glucoside & 22.66 & 4.7 & - & - \\
\hline Rutin & 23.00 & 6.8 & - & - \\
\hline
\end{tabular}

responsible for reduction of metal ions and efficient stabilization of synthesized nanoparticles. Table 2 illustrates the chemical structures of the components found in both extracts.

Thus, the analysis of the composition of the aqueous black currant and apricot pomaces extracts indicated that they contain a wide range of organic substances and therefore are a potential raw material for the use as a reducing and capping agent especially promising for producing nanoscale materials. The reducing power of extracts is a significant indicator of their potential for producing nanoscale materials. The reducing properties of the extracts have connection with their redox behaviour and the electrochemical activity [26]. Cyclic voltammetry is one of the most common techniques to determine reducing power of the extracts [27]. Thus, in this work, the electrochemical oxidation of the black currant and apricot pomace extracts was tested.

The cyclic voltammograms for the black currant and apricot pomace extracts showed no clear reversible peaks but only gave a shoulder and a monotonously increasing peak (Figure 1). Several parameters can be extracted from the cyclic voltammetry curves to characterize the apricot pomace and black currant pomace extracts as reducing agents for producing nanoscale materials. The top scan represents the oxidation of the compounds that are contained in the extracts, generating a positive (anodic) current $I_{\mathrm{a}}=3 \mu \mathrm{A}$, peaking at an electrode potential
$E_{\mathrm{a} 1}=0.52 \mathrm{~V}$ and $E_{\mathrm{a} 1}=0.7 \mathrm{~V}$ for black currant and apricot pomace extracts, respectively. Literature survey reveals that the lower the potential of oxidation is, the stronger the reducing potential of the plant's extract is. Thus, the reducing power is higher for aqueous apricot pomace extract than that for black currant pomace extract. On the reverse scan, a negative (cathodic) peak is not produced; this indicates that the oxidized form of the compounds contained in the extract cannot be reduced back to its original form $[28,29]$.

3.2. Determination of the Synthesis Efficiency. The potential of $\mathrm{Ag}^{+} \mid \mathrm{Ag}$ electrode variation with time is given in Figure 2. The electrode potential corresponds to $\mathrm{Ag}^{+}$concentration in the solution; thus, synthesis process can be monitored. A sharp decrease of the potential is caused by $\mathrm{AgNO}_{3}$ mixing with the extract and the beginning of the synthesis.

Cyclic voltammograms correspond to the $\mathrm{Ag}^{+}$concentration variation during synthesis. Calculated degree of conversion of Ag in the "green" synthesis with black currant pomaces extract is $57.4 \%$ and with apricot pomace extract is $68.7 \%$. The higher abundances of phenolic acids in the apricot pomace aqueous extract may be responsible for the improved AgNP synthesis with it. The concentration of AgNPs in the solution after synthesis with black currant pomaces extract was $45 \mathrm{mg} / \mathrm{L}$ and after synthesis with apricot pomace extract was $59 \mathrm{mg} / \mathrm{L}$. 
TABLE 2: Chemical structures of the common chemical constituents of black currant and apricot pomace extract.

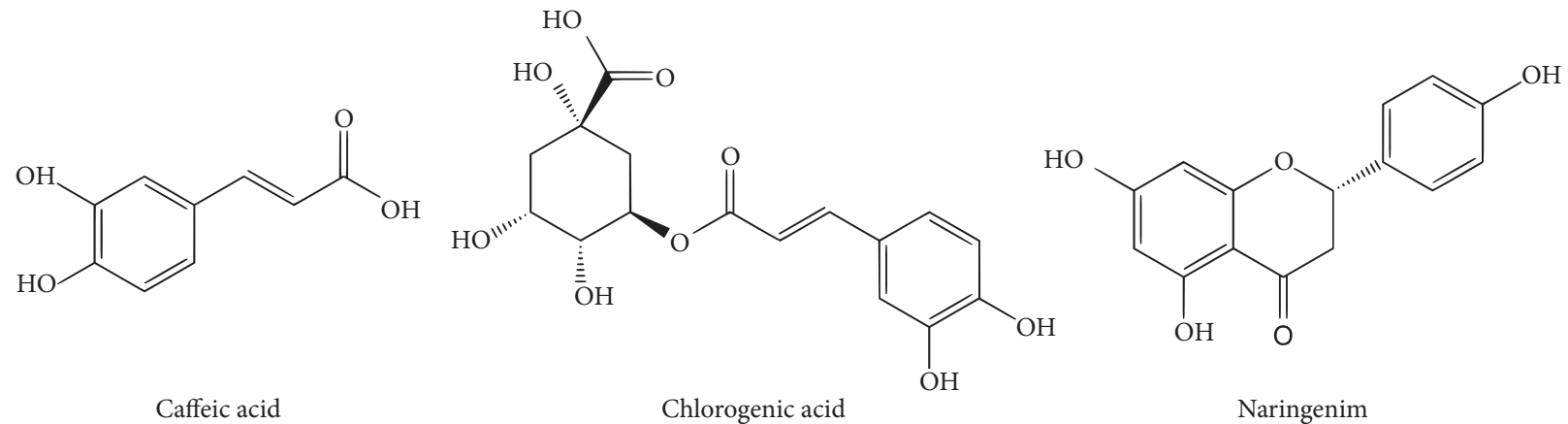

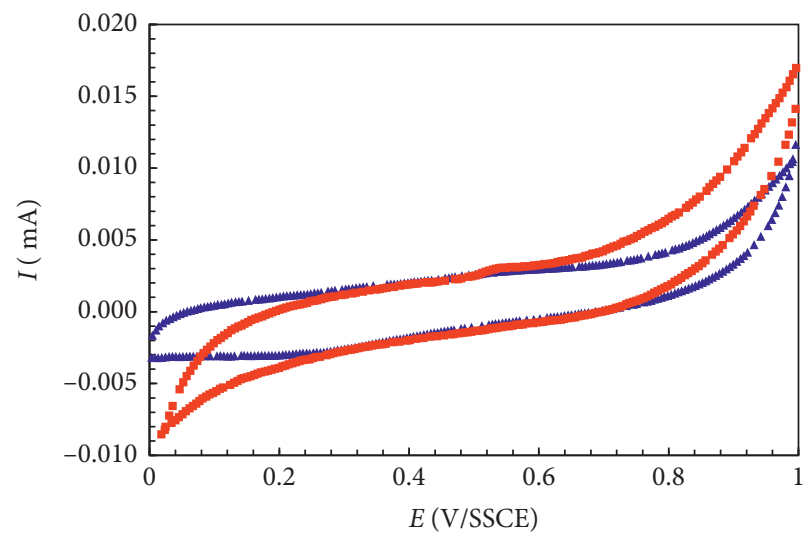

- Black currant

- Apricot

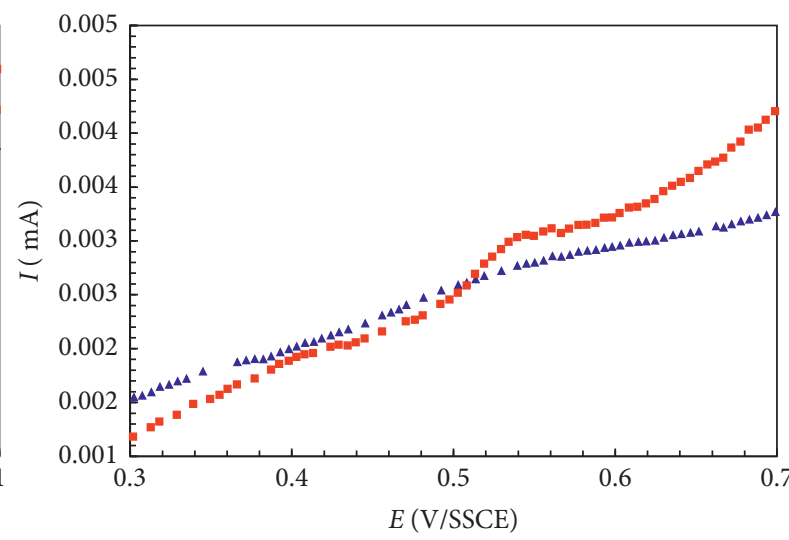

- Black currant

- Apricot

FIGURE 1: Cyclic voltammograms for the black currant and apricot pomace aqueous extracts. Scan rate: $100 \mathrm{mV} / \mathrm{s}$.

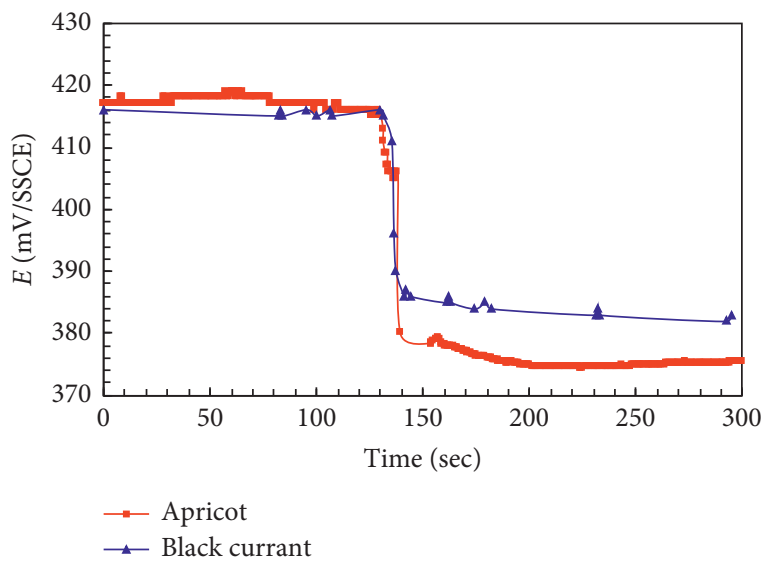

FIGURE 2: $\mathrm{Ag}^{+} \mid$Ag electrode potential variation with time during the "green" synthesis with black currant and apricot pomace extracts at $80^{\circ} \mathrm{C}$.

3.3. AgNP Characterization. The typical surface plasmon resonance (SPR) absorption band was observed at 430 and $390 \mathrm{~nm}$ for the AgNPs obtained with black currant and apricot pomace extracts, respectively (Figure 3). All samples produced a $\lambda_{\max }$ of $420 \mathrm{~nm}$ and were of deep amber colour, indicating the presence of AgNPs. The higher abundances of many phenolic compounds in the black currant pomace extract may be responsible for the improved stability of AgNPs with this extract.

The main characteristics of silver nanoparticles in the dispersed system were investigated, namely, the average size, morphology, and stability of nanoparticles (Table 3). The spherical AgNPs synthesized with black currant pomace extract displayed a particle size of $40-60 \mathrm{~nm}$ with moderate stability (Zeta potential of $-33.41 \mathrm{mV}$ ). The hydrodynamic diameter of AgNPs synthesized using apricot extract was found to be $50-82 \mathrm{~nm}$. The Zeta potential analysis of the synthesized APE-AgNPs showed a peak at value of $-24.3 \mathrm{mV}$. The negative charge of particles has a tendency to provide more stable particles inhibiting the aggregation process [25, 30].

The negatively charged surface of the nanoparticles indicates that anionic capping agents such as polyphenols and flavonoids from the black currant and apricot pomace extracts are coordinated to the surface of silver nanoparticles $[24,29,31]$. To confirm the presence of the crystalline silver in the synthesized AgNPs with aqueous black currant and apricot pomace extracts, EDX patterns were obtained (Figure 4). It is known that AgNPs display typical optical absorption peaks in the range $2.7-3.4 \mathrm{keV}$. The Ag peak 


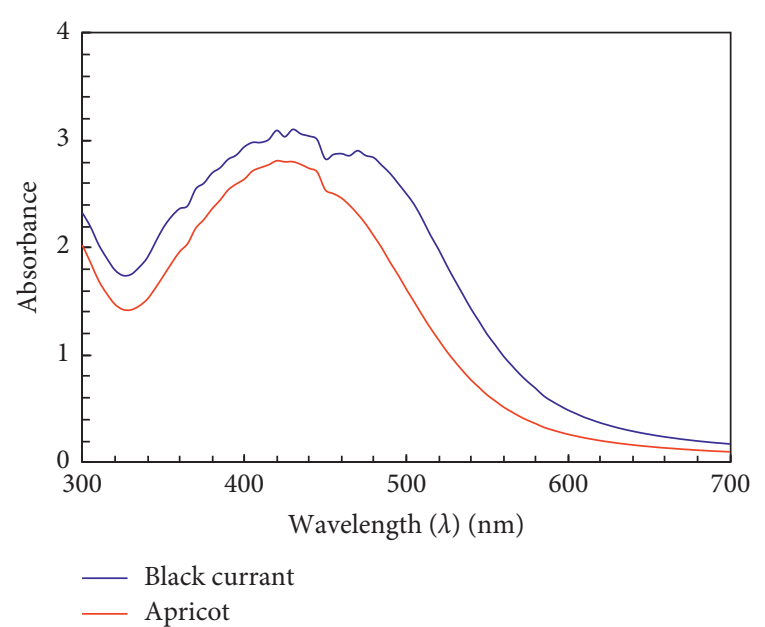

FIgURE 3: UV-Vis absorption spectrum of BCPE-AgNPs (1) and APE-AgNPs (2) after $30 \mathrm{~min}$ of reaction displaying the characteristic surface plasmon resonance band at $430 \mathrm{~nm}$.

TABLE 3: Characteristics of AgNPs synthesized using the BCPE and APE.

\begin{tabular}{lcc}
\hline AgNPs & $\begin{array}{c}\text { Average particle-sized AgNPs } \\
(\mathrm{nm})\end{array}$ & $\begin{array}{c}\text { Zeta potential } \\
(\mathrm{mV})\end{array}$ \\
\hline BCPE- & $40-60$ & -33.41 \\
AgNPs & $50-82$ & -24.23 \\
\hline APE-AgNPs & & \\
\hline
\end{tabular}

could be originated from AgNPs, and other peaks of O and C from the organic compounds of the extracts. Due to the surface plasmon resonance, metallic silver nanocrystals show an absorption peak approximately at $3 \mathrm{keV}$. The presence of the other peaks in the spectra suggests that the $\mathrm{BCPE}-\mathrm{AgNP}$ and APE-AgNPs were surrounded by organic constituents.

The morphology of the AgNPs was examined with SEM (Figure 5). The SEM images revealed the formation of individual silver nanoparticles as well as several aggregates. A greater degree of agglomeration was observed in the suspensions of nanoparticles derived with apricot pomace extract as the reductant, which indicates lower stability of the system. In the meantime, the AgNPs obtained with BCPE do not tend to agglomerate even when solution is diluted before SEM. This confirms higher stabilization properties of BCPE compared to APE.

The FT-IR analysis was used to identify the various functional groups of synthesized AgNPs which were responsible for the reduction of $\mathrm{Ag}^{+}$to $\mathrm{BCPE}-\mathrm{AgNPs}$ and APE-AgNPs (Figure 6).

The FT-IR spectrum of the black currant and apricot pomace extracts shows peaks at around $3400 \mathrm{~cm}^{-1}$ which can be assigned to $v(\mathrm{OH})$ vibrations of polyols such as catechins [30-32]. The $\mathrm{C}-\mathrm{O}$ stretching vibration of the phenolic groups appears as a peak at $1264 \mathrm{~cm}^{-1}$ [30]. The peak at $1652 \mathrm{~cm}^{-1}$ corresponds to the $\mathrm{C}=\mathrm{C}$ vibrations or aromatic ring $\nu(\mathrm{C}=\mathrm{C})$ [26]. The band at $1050 \mathrm{~cm}^{-1}$ is associated with $\mathrm{C}-\mathrm{O}-\mathrm{C}$ stretching vibration. The $\mathrm{C}-\mathrm{O}$ stretching vibration of the phenolic groups appears as a peak at $1251 \mathrm{~cm}^{-1}$. Peak at $500 \mathrm{~cm}^{-1}$ is attributed to aromatic groups. The peak between 1620 and $1660 \mathrm{~cm}^{-1}$ may encompass the $\mathrm{C}=\mathrm{O}$ vibration of bonded carboxylic acids, and the $\mathrm{C}=\mathrm{C}$ vibration of aromatic components.

Comparison of the FTIR spectra of the BCPE and APE and BCPE-AgNPs and APE-AgNPs showed significant difference between the type and intensity of observed peaks. The FTIR spectrum of the synthesized BCPE-AgNPs and APE-AgNPs showed absorption peaks at 1645 and $3440 \mathrm{~cm}^{-1}$. The strong band at $1645 \mathrm{~cm}^{-1}$ is attributed to carbonyl groups involved in the nanoparticle formation [30-32]. The shifts of peaks were observed upon BCPEAgNPs and APE-AgNPs formation such as at 1637 to $1717 \mathrm{~cm}^{-1}, 1465$ to $1452 \mathrm{~cm}^{-1}, 1293$ to $1327 \mathrm{~cm}^{-1}, 1044 \mathrm{~cm}^{-1}$ to $1105 \mathrm{~cm}^{-1}$, and 1713 to $1653 \mathrm{~cm}^{-1}$, indicating the oxidation of corresponding functional groups. The absence of peaks at $1264 \mathrm{~cm}^{-1}, 1289 \mathrm{~cm}^{-1}$, and $1347 \mathrm{~cm}^{-1}$ may be due to the capping action of $\mathrm{C}-\mathrm{O}$ group in the synthesis of AgNPs. The obtained results suggest that the phenolic compounds of the black currant and apricot pomace extracts show vibration stretches in BCPE-AgNPs and APE-AgNPs which might be involved in its formation by acting as capping and stabilizing agents.

The XRD pattern of the synthesized BCPE-AgNPs and APE-AgNPs is provided in Figure 7. Since the XRD technique delivers the information about the geometric arrangements and the distance among the atoms, it is an advantageous technique to support the formation of the nanoparticles. The monoclinic and cubic crystalline planes of the nanoparticles can also be identified by the XRD analysis. The $2 \theta$ peaks observed at $37.90^{\circ}, 64.53^{\circ}$, and $77.38^{\circ}$ correspond to (111), (200), and (311) crystalline planes, respectively. Figure 7 shows the diffraction peaks corresponding to Bragg's from (111), (200), and (311) planes that are relevant to $2 \theta=38^{\circ}, 43^{\circ}$, and $77^{\circ}$, respectively.

XRD result is in good agreement with the various reported values associated with the cubic structure of phytosynthesized AgNPs, thereby confirming the formation of the silver nanocrystals.

3.4. Electrochemical Behaviour of AgNPs. Cyclic voltammetry is one of the most common techniques used in electrochemistry to determine electrochemical activity. Cyclic voltammograms of AgNPs synthesized by black currant and apricot pomace extracts were carried out at scan rate of $100 \mathrm{mVs}^{-1}$.

It was observed that there was a significant difference between oxidation peaks values for AgNPs synthesized using black currant extract as compared to apricot pomace extract. The parameters in Table 4 were obtained from the cyclic voltammograms (Figure 8). The cyclic voltammograms of AgNPs sample show the oxidation peak at $0.42 \mathrm{~V} / \mathrm{SSCE}$ and $0.52 \mathrm{~V} / \mathrm{SSCE}$ prepared using black currant and apricot pomace extract as the reductant, respectively (Figure 8 ). The oxidation of $\mathrm{Ag}(0)$ into $\mathrm{Ag}^{+}$is confirmed by the presence of a peak in the range at 0.05 to $0.45 \mathrm{~V}$ [33]. The difference in the position of oxidation peak potential of the BCPE-AgNPs $(0.53 \mathrm{mV})$ with a diameter of $40-60 \mathrm{~nm}$ and APE-AgNPs 


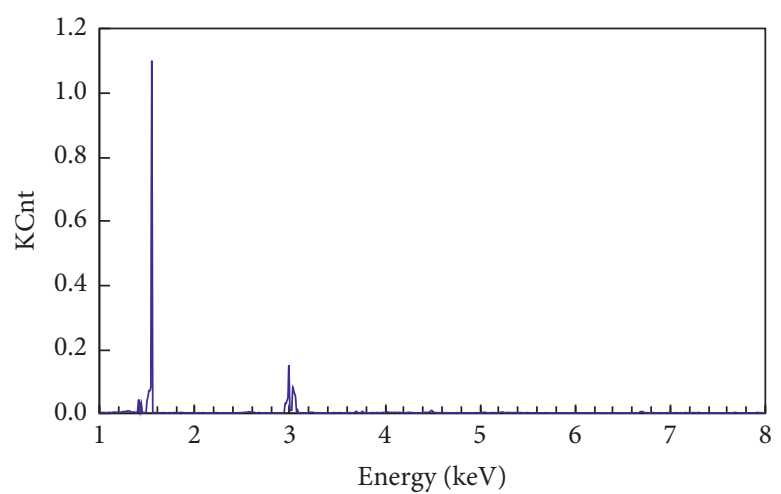

(a)

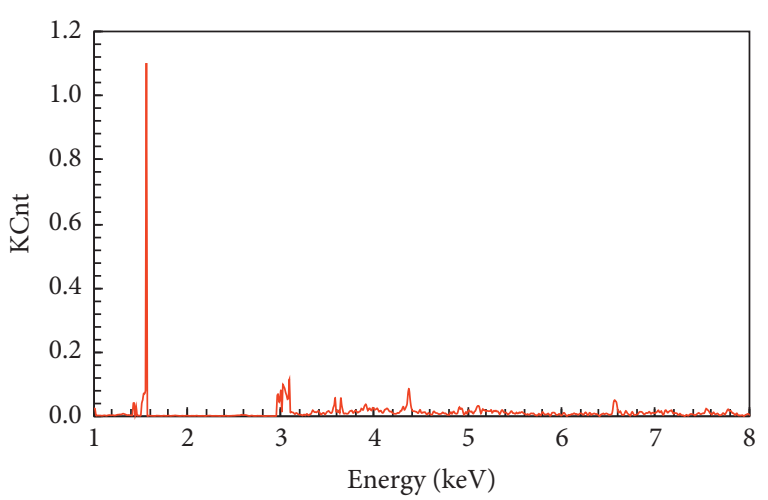

(b)

Figure 4: EDX spectrum of the synthesized BCPE-AgNPs (a) and APE-AgNPs (b).

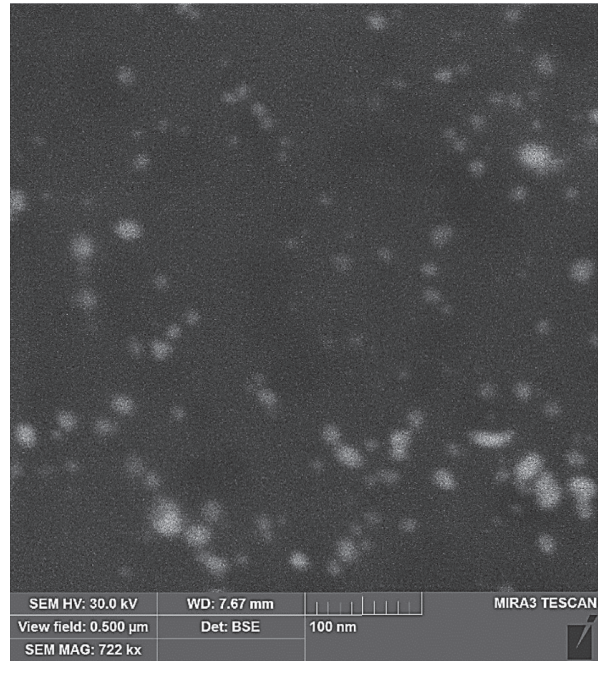

(a)

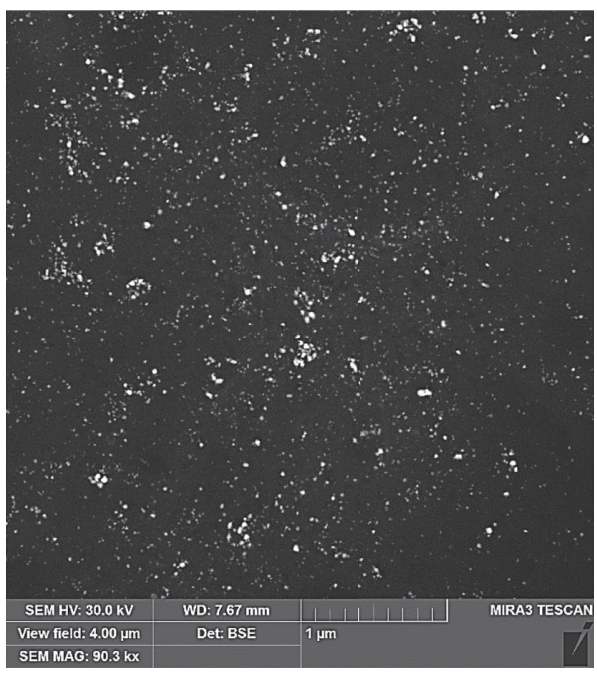

(c)

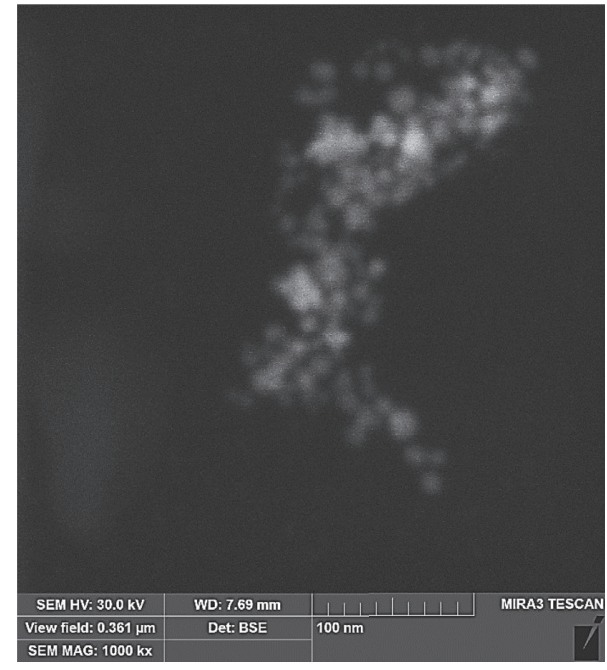

(b)

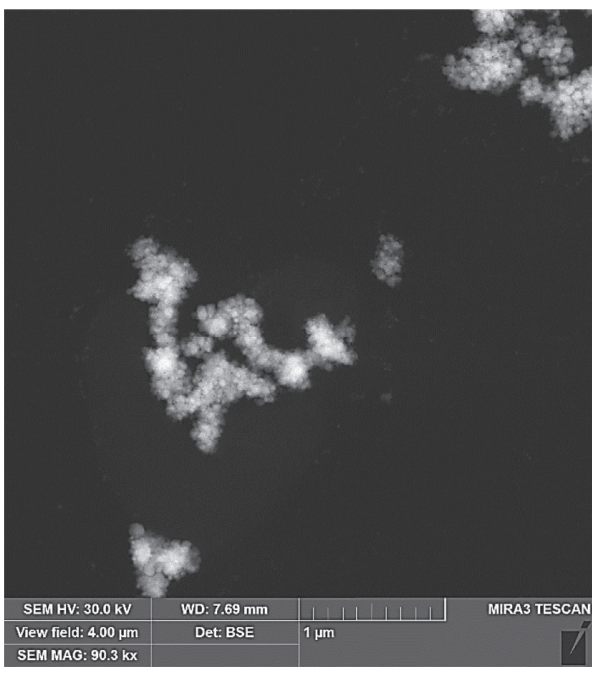

(d)

FiguRE 5: SEM images of obtained silver nanoparticles $\left(\mathrm{C}\left(\mathrm{Ag}^{+}\right)=10 \mathrm{mmol} / \mathrm{L}, \tau=30 \mathrm{~min}\right.$, and ratio $\mathrm{AgNO}_{3}$ : extract of black currant $(\mathrm{a}, \mathrm{b})$ and apricot pomaces $(\mathrm{c}, \mathrm{d})$ extracts $(\mathrm{mL})=1: 1)$. 


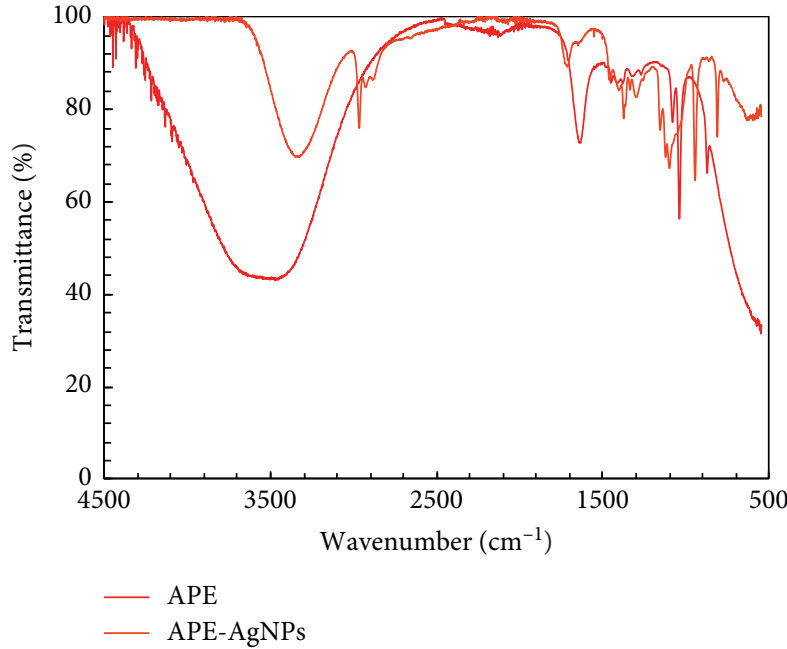

(a)

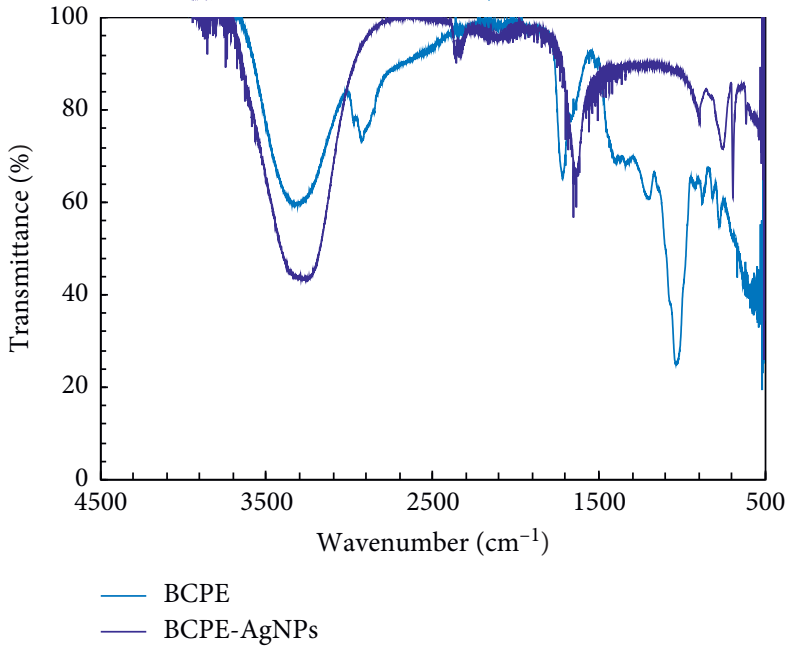

(b)

Figure 6: FT-IR spectra of the black currant and apricot pomace extracts, BCPE-AgNPs and APE-AgNPs.

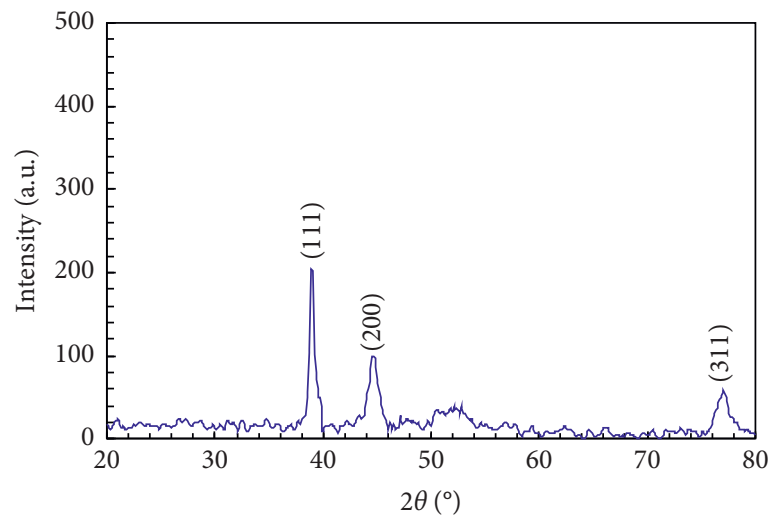

(a)

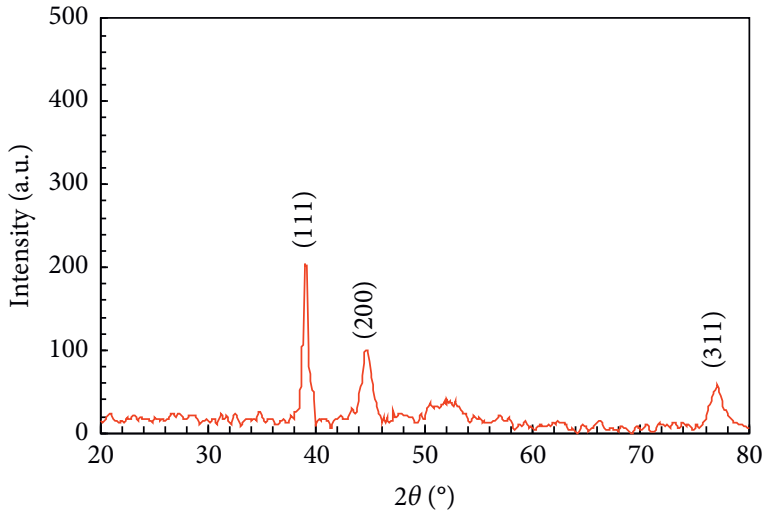

(b)

Figure 7: XRD pattern of the synthesized BCPE-AgNPs (a) and APE-AgNPs (b).

TABLE 4: Cyclic voltammetry characteristics of aqueous black currant and apricot pomaces extracts.

\begin{tabular}{lcccc}
\hline Extract & $I_{\mathrm{p} . \mathrm{a}}(\mu \mathrm{A})$ & $E_{\mathrm{p} . \mathrm{a}}(\mathrm{V})$ & $E_{\mathrm{p} . \mathrm{a}}-E_{\mathrm{p} / 2}(\mathrm{~V})$ & \\
\hline BCPE-AgNPs & 91 & 0.44 & 0.05 & $I_{\mathrm{p}, \mathrm{a}} / I_{\mathrm{p}, \mathrm{c}}$ \\
APE-AgNPs & 160 & 0.53 & 0.07 & 4.5 \\
\hline
\end{tabular}

$(0.44 \mathrm{mV})$ with an average diameter of $50-82 \mathrm{~nm}$ could be due to the difference in the sizes of AgNPs.

3.5. Antimicrobial Activity of AgNPs. Low values of optical density (“0" or less than " 0.075 ") and absolute absence of bacteria growth on Endo agar allow us to determinate the minimal bactericidal concentration (MBC) of each sample of AgNPs solutions. To estimate and compare the minimal inhibitory concentrations of different AgNPs solutions, a graphical method has been used: agent concentration, which corresponds to the half value of optical density in relation of control tube in each sample, was determined (Figure 9).
As experimental result demonstrated, the AgNPs obtained with black currant pomace extract have MBC of $10 \%$ and MIC of $4.2 \%$, but for apricot pomace extract MBC is $33 \%$ and MIC 7.5\%. Therefore, silver nanosystem, obtained with black currant pomace extract, has stronger bactericidal properties than the other one, obtained with apricot pomace extract.

3.6. Antioxidant Properties of AgNPs. The evaluation of the antioxidant properties of "green" synthesized silver nanoparticles is useful to establish their potential applications in the food, pharmaceutical, and cosmetic industries [34, 35]. It 


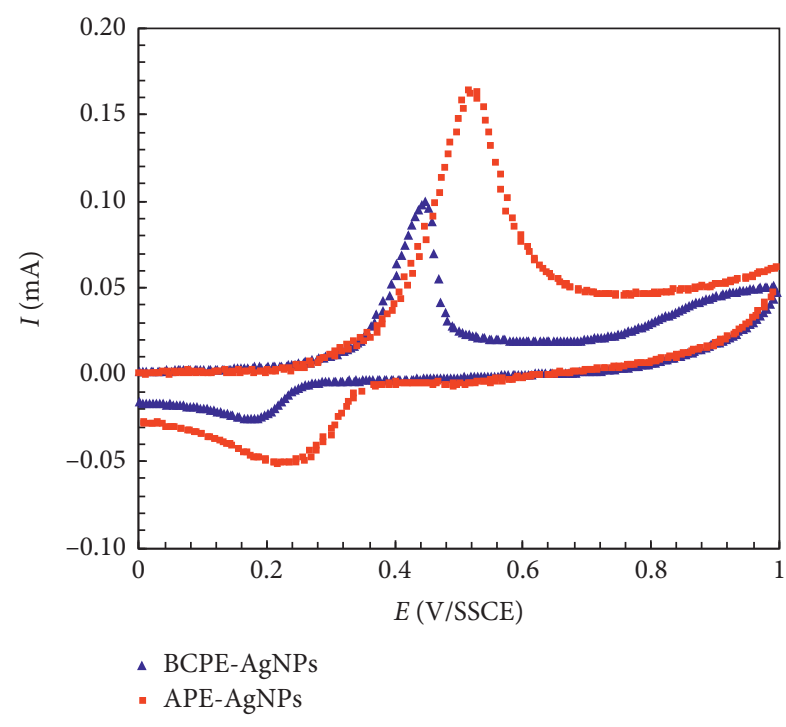

Figure 8: Cyclic voltammograms of BCPE-AgNPs and APEAgNPs at a scan rate of $100 \mathrm{mVs}^{-1}$ in acetate buffer $0.1 \mathrm{M}(\mathrm{pH} 4)$ and $\mathrm{NaClO}_{4}(70: 28: 2)$.

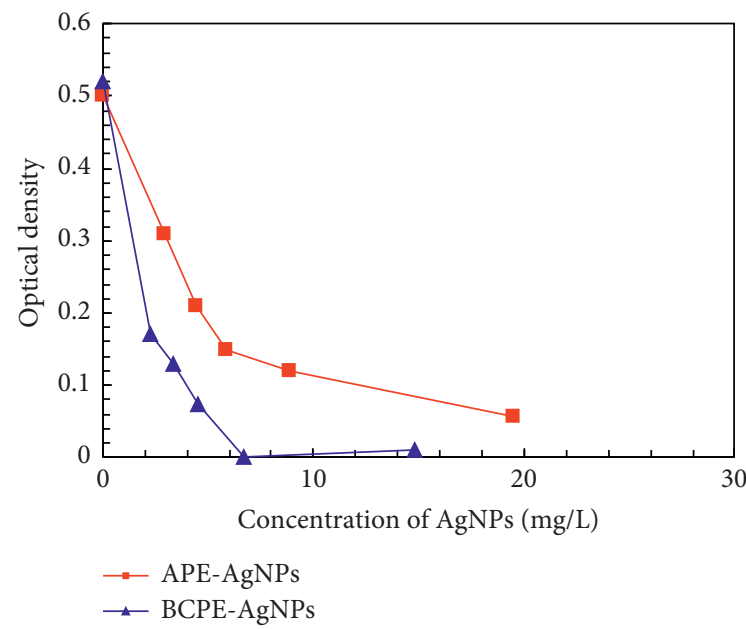

FIgURe 9: Optical density of test tubes with E. coli culture and different concentration of AgNPs obtained with apricot (1) and black current (2) pomace extracts after 24-hour cultivation.

is clearly observed that both the BCPE-AgNPs and APEAgNPs are potential free radical scavengers with effective inhibition activity in a dose-dependent manner. The BCPEAgNPs and APE-AgNPs showed higher antioxidant activity than the extracts used in the synthesis. The DPPH scavenging activity exhibited potent inhibition of BCPE-AgNPs and APE-AgNPs activity when compared with standard, while BHT (Figure 10) was utilized as a positive control. The negative control effect of antioxidant screening obtained with ethanol was $2.1 \%$.

The efficient free radical scavenging properties of the BCPE-AgNPs and APE-AgNPs could be due to the combined effect of both AgNPs as well as of the organic compounds present in the black currant and apricot pomaces extracts. The BCPE-AgNPs and APE-AgNPs nanoparticles could show two types of radical scavenging reactions such as

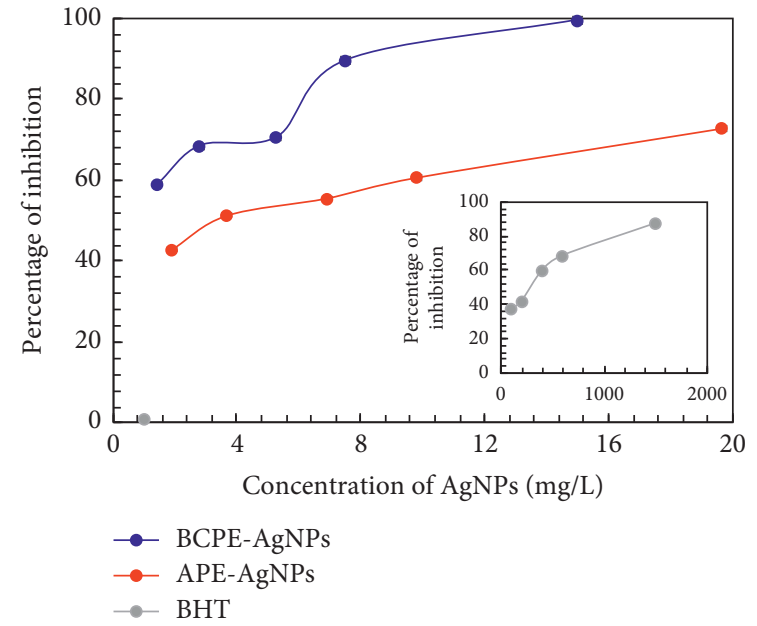

Figure 10: DPPH radical activity of the BCPE-AgNPs and APEAgNPs.

rapid $\mathrm{H}$-atom transfer and secondary/slow radical-radical coupling reactions [34]. The obtained result agreed with the other studies, which showed that the antioxidant activity of "green" synthesized AgNPs was more than an extract [35].

\section{Discussion}

Thus, it can be concluded that the higher reducing potential of the apricot pomace extract leads to the more efficient synthesis of silver nanoparticles. However, it seems that apricot pomace extract does not have the capping agent in the necessary quantity to ensure colloidal stability of the system. On the other hand, a low reducing potential, combined with a good capping activity of the main compounds of the black currant pomace extract, leads to the synthesis of nanoparticles with a smaller size and higher antioxidant and antibacterial properties. Several flavonoids, which were found in the black currant pomaces extract, are presented by the flavonol glycosides. The glucosides in the structure of the flavonol glycosides are present in the extract and may be responsible for the more efficient stabilization of synthesized nanoparticles solutions. The data obtained are consistent with the results of the authors that established that the $-\mathrm{COOH}$ groups of phenolics and flavonoids in the leaf extract were found to be responsible for the reduction of $\mathrm{Ag}^{+}$ions, while $\mathrm{C}=\mathrm{O}$ groups of the glycosides contributed to the stabilization of NPs.

\section{Conclusions}

Silver nanoparticles were synthesized by the reduction of silver ions with the black currant and apricot pomace aqueous extracts. Detailed gas chromatography-mass spectrometry (LC-MS) results established that polyphenols were present in the extracts (34-60\%) and could serve as reducing agents in synthesis. Probably, after reduction of $\mathrm{AgNO}_{3}$ the subsequent capping of AgNPs occurred through the action of flavonol glycosides that were found in the black currant pomaces extract $(\sim 28 \%)$. In the meantime, the use of 
apricot pomace extract appeared to be more efficient at the stage of nanoparticle synthesis; however, for colloidal stabilization of APE-AgNPs system it was not as reliable. Electrochemical analysis of aqueous black currant and apricot pomace extracts provides significant information about the reducing ability of the extracts. The apricot pomace extract showed higher reducing power measured by electrochemical methods, as well as higher efficiency for the "green" synthesis of silver nanoparticles. The synthesized BCPE-AgNPs and APE-AgNPs exhibit a spherical shape with small size (40 to $60 \mathrm{~nm}$ ), uniform dispersion, and high stability. FT-IR spectra showed the presence of organic constituents in BCPE-AgNPs and APE-AgNPs colloids, indicating the engagement of organic components of BCPE and APE as reducing and capping agents in the synthesis process of AgNPs. The inhibitory efficacy (MIC) of Gramnegative microorganisms Escherichia coli was observed for $4.2 \%$ and $7.5 \%$ solutions of BCPE-AgNPs and APE-AgNPs, respectively. The antioxidant results indicate that the silver nanoparticles showed excellent scavenging rate against DPPH free radicals $(40-99 \pm 1.2 \%)$.

\section{Data Availability}

All data generated or analysed during this study are included within the article.

\section{Conflicts of Interest}

The authors declare that they have no conflicts of interest.

\section{Acknowledgments}

This work was supported by the Ministry of Education and Science of Ukraine (grant no. 2223, 2019).

\section{References}

[1] S.-j. Yu, Y.-g. Yin, and J.-f. Liu, "Silver nanoparticles in the environment," Environmental Science: Processes \& Impacts, vol. 15, no. 1, pp. 78-92, 2013.

[2] Q. H. Tran, V. Q. Nguyen, and A.-T. Le, "Silver nanoparticles: synthesis, properties, toxicology, applications and perspectives," Advances in Natural Sciences: Nanoscience and Nanotechnology, vol. 4, no. 3, Article ID 033001, 2013.

[3] B. Bhattarai, Y. Zaker, and T. P. Bigioni, "Green synthesis of gold and silver nanoparticles: challenges and opportunities," Current Opinion in Green and Sustainable Chemistry, vol. 12, pp. 91-100, 2018.

[4] N. Savithramma, M. L. Rao, K. Rukmini, and P. S. Devi, "Antimicrobial activity of silver nanoparticles synthesized by using medicinal plants," International Journal of Chem Tech Research, vol. 3, no. 3, pp. 1394-1402, 2011.

[5] M.-C. Daniel and D. Astruc, "Gold nanoparticles: assembly, supramolecular chemistry, quantum-size-related properties, and applications toward biology, catalysis, and nanotechnology," Chemical Reviews, vol. 104, no. 1, pp. 293-346, 2004.

[6] M. Darroudi, M. B. Ahmad, A. H. Abdullah, N. A. Ibrahim, and K. Shameli, "Effect of accelerator in green synthesis of silver nanoparticles," International Journal of Molecular Sciences, vol. 11, no. 10, pp. 3898-3905, 2010.
[7] R. S. R. Isaac, G. Sakthivel, and C. Murthy, "Green synthesis of gold and silver nanoparticles using Averrhoabilimbi fruit extract," Journal of Nanotechnology, vol. 2013, Article ID 906592, 6 pages, 2013.

[8] S. S. Shankar, A. Rai, A. Ahmad, and M. Sastry, "Rapid synthesis of $\mathrm{Au}, \mathrm{Ag}$, and bimetallic $\mathrm{Au}$ core-Ag shell nanoparticles using neem (Azadirachta indica) leaf broth," Journal of Colloid and Interface Science, vol. 275, no. 2, pp. 496-502, 2004.

[9] B. Ankamwar, C. Damle, A. Ahmad, and M. Sastry, "Biosynthesis of gold and silver nanoparticles using Emblica officinalis fruit extract, their phase transfer and transmetallation in an organic solution," Journal of Nanoscience and Nanotechnology, vol. 5, no. 10, pp. 1665-1671, 2005.

[10] P. R. Reddy, S. D. Ganesh, N. Saha, O. Zandraa, and P. Sáha, "Ecofriendly synthesis of silver nanoparticles from garden rhubarb (Rheum rhabarbarum)," Journal of Nanotechnology, vol. 2016, Article ID 4964752, 9 pages, 2016.

[11] M. Z. H. Khan, F. K. Tarek, M. Nuzat, M. A. Momin, and M. R. Hasan, "Rapid biological synthesis of silver nanoparticles from ocimum sanctum and their characterization," Journal of Nanoscience, vol. 2017, Article ID 1693416, 6 pages, 2017.

[12] M. Skiba, A. Pivovarov, A. Makarova, and V. Vorobyova, "Plasma-chemical synthesis of silver nanoparticles in the presence of citrate," Chemistry Journal of Moldova, vol. 13, no. 1, pp. 7-14, 2018.

[13] M. Skiba, A. Pivovarov, A. Makarova, and V. Vorobyova, "Plasmochemical preparation of silver nanoparticles: thermodynamics and kinetics analysis of the process," EasternEuropean Journal of Enterprise Technologies, vol. 2, no. 6, pp. 4-9, 2018.

[14] A. Saravanakumar, M. Ganesh, J. Jayaprakash, and H. T. Jang, "Biosynthesis of silver nanoparticles using Cassia tora leaf extract and its antioxidant and antibacterial activities," Journal of Industrial and Engineering Chemistry, vol. 28, pp. 277-281, 2015.

[15] N. Basavegowda, A. Idhayadhulla, and Y. R. Lee, "Phytosynthesis of gold nanoparticles using fruit extract of Hovenia dulcis and their biological activities," Industrial Crops and Products, vol. 52, pp. 745-751, 2014.

[16] G. Lakshmanan, A. Sathiyaseelan, P. T. Kalaichelvan, and K. Murugesan, "Plant-mediated synthesis of silver nanoparticles using fruit extract of Cleome viscosa L.: assessment of their antibacterial and anticancer activity," Karbala International Journal of Modern Science, vol. 4, no. 1, pp. 61-68, 2018.

[17] M. Shaik, M. Khan, M. Kuniyil et al., "Plant-extract-assisted green synthesis of silver nanoparticles using Origanum vulgare L. extract and their microbicidal activities," Sustainability, vol. 10, no. 4, pp. 913-927, 2018.

[18] S. S. Shankar, A. Ahmad, and M. Sastry, "Geranium leaf assisted biosynthesis of silver nanoparticles," Biotechnology Progress, vol. 19, no. 6, pp. 1627-1631, 2003.

[19] Guidelines (MUK), Opredelenie Chuvstvitelnosti Mikroorganizmov $K$ Antibakteialnym Preparatam: Metodicheskie Ukazaniia. (Determination of the Sensitivity of Microorganisms to Antibacterial Drugs: Guidelines), Moscow: Federal Center for State Sanitary and Epidemiological Supervision of the Ministry of Health of Russia, Moskow, Russia, 2004.

[20] K. Thaipong, U. Boonprakob, K. Crosby, L. Cisneros-Zevallos, and D. Byrne Hawkins, "Comparison of ABTS, DPPH, FRAP, and ORAC assays for estimating antioxidant activity from 
guava fruit extracts," Journal of Food Composition and Analysis, vol. 19, no. 6-7, pp. 669-675, 2006.

[21] O. A. Pivovarov, M. I. Skiba, A. K. Makarova, and V. I. Vorobyova, "One-pot synthesis of silver nanoparticles using nonequilibrium low temperature plasma in the presence of polyvinyl alcohol," Voprosy Khimii i Khimicheskoi Tekhnologii, vol. 3, pp. 113-120, 2018.

[22] M. Skiba and V. Vorobyova, "Green synthesis of silver nanoparticles using grape pomace extract prepared by plasma-chemical assisted extraction method," Molecular Crystals and Liquid Crystals, vol. 671, no. 1, pp. 142-151, 2018.

[23] R. D. Rivera-Rangel, M. P. González-Muñoz, M. AvilaRodriguez, T. A. Razo-Lazcano, and C. Solans, "Green synthesis of silver nanoparticles in oil-in-water microemulsion and nano-emulsion using geranium leaf aqueous extract as a reducing agent," Colloids and Surfaces A: Physicochemical and Engineering Aspects, vol. 536, pp. 60-67, 2018.

[24] Z. Wang, C. Xu, X. Li, and Z. Liu, "In situ green synthesis of Ag nanoparticles on tea polyphenols-modified graphene and their catalytic reduction activity of 4-nitrophenol," Colloids and Surfaces A: Physicochemical and Engineering Aspects, vol. 485, pp. 102-110, 2015.

[25] C. Jayaseelan, R. Ramkumar, A. A. Rahuman, and P. Perumal, "Green synthesis of gold nanoparticles using seed aqueous extract of Abelmoschus esculentus and its antifungal activity," Industrial Crops and Products, vol. 45, pp. 423-429, 2013.

[26] G. I. Giles, C. A. Collins, T. W. Stone, and C. Jacob, "Electrochemical and in vitro evaluation of the redox-properties of kynurenine species," Biochemical and Biophysical Research Communications, vol. 300, no. 3, pp. 719-724, 2003.

[27] J. F. Arteaga, M. Ruiz-Montoya, A. Palma, G. Alonso-Garrido, S. Pintado, and J. M. Rodríguez-Mellado, "Comparison of the simple cyclic voltammetry (CV) and DPPH assays for the determination of antioxidant capacity of active principles," Molecules, vol. 17, no. 5, pp. 5126-5138, 2012.

[28] E. Elemike, O. Fayemi, A. Ekennia, D. Onwudiwe, and E. Ebenso, "Silver nanoparticles mediated by Costus afer leaf extract: synthesis, antibacterial, antioxidant and electrochemical properties," Molecules, vol. 22, no. 5, pp. 701-722, 2017.

[29] I. Y. L. de Macêdo, L. F. Garcia, J. R. Oliveira Neto et al., "Electroanalytical tools for antioxidant evaluation of red fruits dry extracts," Food Chemistry, vol. 217, pp. 326-331, 2017.

[30] T. J. I. Edison and M. G. Sethuraman, "Biogenic robust synthesis of silver nanoparticles using Punica granatum peel and its application as a green catalyst for the reduction of an anthropogenic pollutant 4-nitrophenol," Spectrochimica Acta Part A: Molecular and Biomolecular Spectroscopy, vol. 104, pp. 262-264, 2013.

[31] M. F. Zayed, W. H. Eisa, S. M. El-kousy, W. K. Mleha, and N. Kamal, "Ficus retusa-stabilized gold and silver nanoparticles: controlled synthesis, spectroscopic characterization, and sensing properties," Spectrochimica Acta Part A: Molecular and Biomolecular Spectroscopy, vol. 214, pp. 496-512, 2019.

[32] Z. U. H. Khan, A. Khan, A. Shah et al., "Enhanced photocatalytic and electrocatalytic applications of green synthesized silver nanoparticles," Journal of Molecular Liquids, vol. 220, pp. 248-257, 2016.

[33] I. Khalil, W. A. Yehye, A. E. Etxeberria et al., "Nanoantioxidants: recent trends in antioxidant delivery applications," Antioxidants, vol. 9, no. 1, pp. 24-54, 2019.

[34] M. P. Das, J. R. Livingstone, P. Veluswamy, and J. Das, "Exploration of wedelia chinensis leaf-assisted silver nanoparticles for antioxidant, antibacterial and in vitro cytotoxic applications," Journal of Food and Drug Analysis, vol. 26, pp. 917-925, 2018.

[35] M. F. Zayed, R. A. Mahfoze, S. M. El-kousy, and E. A. AlAshkar, "In-vitro antioxidant and antimicrobial activities of metal nanoparticles biosynthesized using optimized Pimpinella anisum extract," Colloids and Surfaces A: Physicochemical and Engineering Aspects, vol. 585, Article ID 124167, 2020. 